\title{
Multimodality intravascular imaging of bioresorbable vascular scaffolds implanted in vein grafts
}

\author{
Tomasz Roleder ${ }^{1}$, Elzbieta Pociask², Wojciech Wanha³, Pawel Gasior ${ }^{3}$, Magdalena Dobrolinska ${ }^{3}$, \\ Magdalena Garncarek ${ }^{1}$, Przemyslaw Pietraszewski ${ }^{4}$, Radoslaw Kurzelowski ${ }^{3}$, Grzegorz Smolka ${ }^{3}$, \\ Wojciech Wojakowski ${ }^{3}$
}

${ }^{1}$ Regional Specialist Hospital, Research and Development Center, Wroclaw, Poland

${ }^{2}$ Department of Biocybernetics and Biomedical Engineering, AGH University of Science and Technology, Krakow, Poland ${ }^{3}$ Department of Cardiology and Structural Heart Diseases, $3^{\text {rd }}$ Division of Cardiology, Medical University of Silesia, Katowice, Poland ${ }^{4}$ Department of Sports Theory, Jerzy Kukuczka Academy of Physical Education, Katowice, Poland

Adv Interv Cardiol 2019; 15, 2 (56): 151-157

DOI: https://doi.org/10.5114/aic.2019.86010

\begin{abstract}
A bstract
Introduction: There are no data presenting a serial assessment of vein graft healing after bioresorbable vascular scaffold (BVS) implantation at long-term follow-up.

Aim: To describe ABSORB BVS healing in vein grafts by optical coherence tomography (OCT) and high-definition intravascular imaging (HD-IVUS) at long-term follow-up.

Material and methods: The study group consisted of 6 patients. The first patient had serial OCT assessment of BVS implanted in the saphenous vein grafts (SVG) at baseline and at 3-, 6-, 18-month follow-up and the second patient had OCT assessment of BVS implanted in the SVG at baseline and 24-, 48-month follow-up. The second and the third patients had OCT and HD-IVUS imaging at baseline and 48-month follow-up. The last 3 patients had OCT imaging of BVS implanted in the native coronary artery at 48-month follow-up.

Results: There were no differences in neointimal hyperplasia after BVS implantation between each time point. However, complete scaffold coverage was observed only 48 months after implantation. Out of 202 analyzed scaffold struts, there were 67 (33\%) black boxes detectable at 48-month follow-up. HD-IVUS presented plaque burden up to $67 \%$ at the segment of BVS implantation at 48-months follow-up. There was a difference in neointimal hyperplasia thickness (1.27 (0.953-1.696) vs. 0.757 (0.633-0.848), $p<0.001)$ between a native coronary artery and BVS scaffolds at 48-month follow-up.

Conclusions: Bioresorbable vascular scaffold implanted in SVG characterized moderate neointimal hyperplasia as excessive as compared to native coronary arteries at long-term follow-up. The complete scaffold coverage was observed only 48 months after implantation.
\end{abstract}

Key words: ABSORB, vein graft, optical coherence tomography, high-definition intravascular ultrasound.

Su m m a ry

This study sought to describe bioresorbable vascular scaffold (BVS) ABSORB healing in vein grafts by optical coherence tomography (OCT) and high-definition intravascular imaging (HD-IVUS) at long-term follow-up. Complete scaffold coverage was observed only 48 months after implantation. There was a difference in NIH thickness (1.27 (0.953-1.696)] vs. 0.757 (0.633-0.848), $p<0.001)$ between a native coronary artery and BVS scaffolds at 48-month follow-up. HD-IVUS presented plaque burden up to $67 \%$ at the segment of BVS implantation in the vein graft at 48 -month follow-up.

\section{Introduction}

In the last years, implantation of bioresorbable vascular scaffolds (BVS) have attracted worldwide interest as an equally valuable alternative to drug-eluting stents to treat coronary vessel disease. The outcomes of the first clinical trials were so promising that BVS implantation

\section{Corresponding author:}

Tomasz Roleder MD, PhD, Regional Specialist Hospital, Research and Development Center, 73a Kamieńskiego St, 51-124 Wroclaw, Poland, phone: +48 884096 034, e-mail: tomaszroleder@gmail.com

Received: 30.12.2018, accepted: 28.02.2019. 
became a commonly accepted therapy of coronary artery disease [1, 2]. Bioresorbable vascular scaffolds was not only used to treat simple coronary lesions but was also implanted in bifurcations, chronic total occlusions, instent restenosis and de novo lesion of saphenous grafts [3-6]. Unfortunately, the initial enthusiasm vanished because the long patient follow-up resulted in increased incidence of late scaffold thrombosis after BVS implantation [7, 8].

Although BVS implantation is now not recommended during percutaneous coronary interventions [9], its remodeling and healing in a different clinical setting have not been comprehensively described yet [10]. One such unusual clinical scenario is the implantation of BVS to de novo lesions of vein grafts $[11,12]$.

The first clinical observations presented promising results of BVS implantation in vein grafts, and intravascular imaging presented favorable vein graft healing after BVS implantation at short-term follow-up $[5,13,14]$. However, there were no data presenting a serial assessment of vein graft healing after BVS implantation at long-term follow-up.

\section{Aim}

The following study sought to describe BVS healing in vein grafts by optical coherence tomography (OCT) and high-definition intravascular imaging (HD-IVUS) at longterm follow-up. The obtained results were compared with BVS healing in native coronary arteries.

\section{Material and methods}

It was a single center study evaluating the vessel healing after BVS ABSORB (Abbott Laboratories, USA) [1] implantation in vein grafts by multimodality imaging including optical coherence imaging (OCT) and high-definition intravascular ultrasound (HD-IVUS) in patients with stable coronary artery disease (CAD) and acute coronary syndromes (ACS). The study was approved by the Ethics Committee of the Medical University of Silesia (KNW/0022/KB1/39/18) and conforms to the Declaration of Helsinki. All of the patients were enrolled in the study only after the patients gave their informed written consent.

\section{Inclusion/exclusion criteria}

The study included patients with a history of coronary artery bypass grafting (CABG) utilizing vein grafts with recurrent stable CAD or ACS to implant and to perform serial intravascular imaging of BVS. Furthermore, the study included patients 48 months after BVS implantation in native coronary arteries to compare vessel healing after BVS implantation between SVG and native coronary arteries. The study exclusion criteria were as follows: age $<18$ years old, glomerular filtration rate less than $45 \mathrm{ml}$ $\min / 1.73 \mathrm{~m}^{2}$, severe valve disease warranting redo cardiac surgery and contrast allergy.

\section{Optical coherence tomography imaging}

Optical coherence tomography imaging was performed after the scaffold implantation in SVG and at the follow-up. It was also performed 48 months after BVS implantation in native coronary arteries. The St Jude iLumien OPTIS Medical system was used for OCT imaging. The OCT probe (a mid marker of the OCT Dragonfly catheter) was positioned $5 \mathrm{~mm}$ distally to the scaffold intended to analyze. All OCT imaging was performed using automated pullback triggered by the manual injection of contrast.

\section{Optical coherence tomography image analysis}

CASS intravascular software 2.0 (Pie medical company) was used for offline analysis of the implanted BVS. The region of interest was selected between the proximal and distal edges of the BVS visible by OCT as struts occupying more than 180 degrees of the lumen's circumference. The analysis was performed every $1 \mathrm{~mm}$ to measure lumen area (LA), lumen diameters (LD) and endoluminal and out scaffold area (SA). Endoluminal SA was measured at the inter circumference of polymeric struts and out SA was measured at the outer rim of polymeric struts. The eccentric index (EI) was measured as follows: $\mathrm{EI}=1-($ minimal lumen $\mathrm{area} / \mathrm{maximal}$ lumen area). Lesions with $\mathrm{El}>0.3$ were defined as eccentric lesions.

Polymeric struts apposition was also assessed, and if there was a gap between the polymeric strut and the vessel's lumen contour, malapposition was diagnosed [15]. At the follow-up, polymeric struts' coverage by neointima was also assessed. The complete coverage of BVS by neointima was identified if four corners of the polymeric strut had lost the right-angle shape with signs of tissue coverage [16]. To measure the tissue thickness the distance from every black box to the lumen contour was measured. Since the thickness of the BVS contours is $30 \mu \mathrm{m}$, this value was subtracted from the final tissue measurement to present neointimal hyperplasia $(\mathrm{NIH}$, $\mu \mathrm{m})$. Neointimal area was measured by subtracting as follows: endoluminal SA - (lumen area + malapposition area).

\section{HD-IVUS image analysis}

HD-IVUS imaging was performed using the ACIST HDi system and ACIST Kodama IVUS catheter device. The region of interest was the segment of the artery where the BVS was previously implanted. Quantitative grey-scale IVUS measurements were performed every millimeter in scanned coronary segments. Cross-sectional images were quantified for lumen diameters and area, external elastic membrane (EEM) diameters and area, total plaque area (TPA) and plaque burden (PB). Since all HD-IVUS imaging was performed at 48 months after implantation no BVS 
strut detection was performed. TPA was calculated as the difference between EEM area, and PB was calculated as total plaque area (TPA) divided by EEM area $\times 100$ (\%).

\section{Statistical analysis}

Continuous parameters were reported as mean with standard deviation and median with the first and the third quartiles. Discrete data were summarized as frequencies and group percentages. Wilcoxon signed-rank test and the $\chi^{2}$ test with Rao and Scott adjustment were used for comparison of continuous and categorical data, respectively. $P$-value $<0.05$ was considered statistically significant. Analyses for statistical computing were performed using MedCalc version 18.6 (MedCalc Software, Belgium).

\section{Results}

\section{Study group}

The study group consisted of 6 patients. Forty-eight months imaging was performed in 5 patients. The first one could not have the intravascular imaging at 48-month follow-up because she died 40 months after BVS implantation due to a non-cardiac cause (lympho-

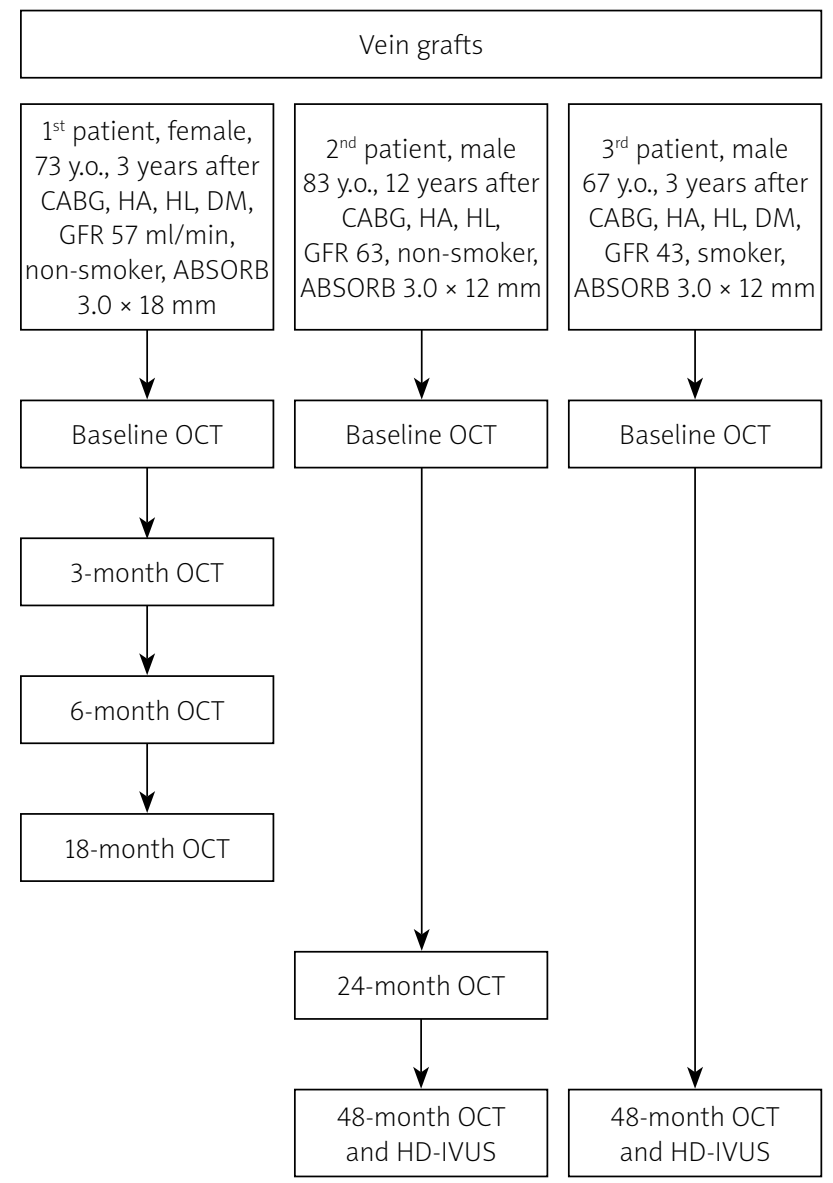

$\mathrm{ma}$ ). The others did not experience any adverse cardiac events at 48-month follow-up. All patients received DAPT for the 12 months after BVS implantation. Patients and BVS characteristics, and the study flow chart are presented in Figure 1.

\section{Serial OCT follow-up of BVS after its implantation in SVG}

The first BVS was observed at baseline and at 3, 6 and 18 months after implantation. The MLA and MLD decreased after 3 months, and then it significantly increased at 18 months. There were no differences in $\mathrm{NIH}$ and the neointimal area between each time point respectively. Interestingly, endoluminal SA was systematically increasing at each time point, but the out SA increased only in the sixth month after BVS implantation (Figure 1, Table I). The second BVS was observed at baseline, 24 and 48 months after its implantation. MLA and MLD decreased at 24- and 48-month follow-up as compared to baseline values (Table I). There were no differences in $\mathrm{NIH}$ and the neointimal area between each time point. The endoluminal SA and out SA increased over the time of observation (Figure 2, Table I).

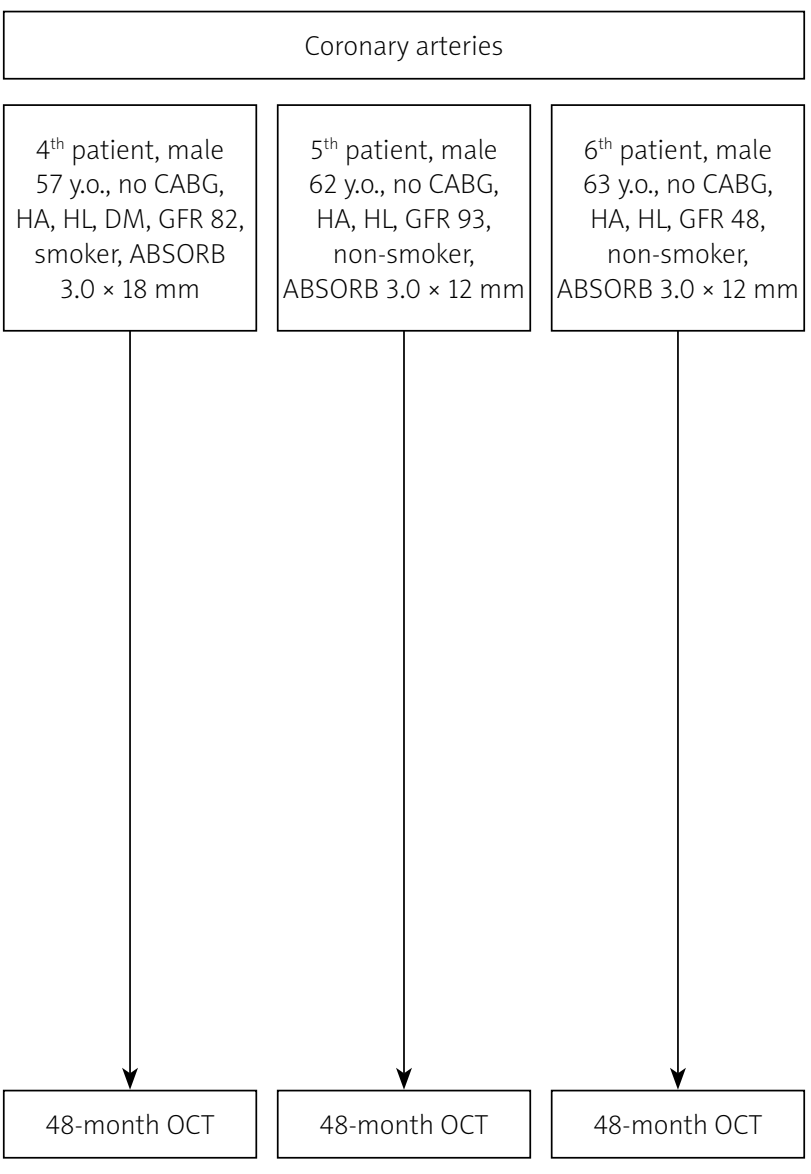

Figure 1. Study chart flow. The study chart flow presents the time of optical coherence tomography (OCT) and high definition intravascular (HD-IVUS) imaging of ABSORB implanted in vein grafts and coronary arteries 
Table I. Serial OCT assessment of ABSORB scaffold implanted in SVG

\begin{tabular}{|c|c|c|c|c|c|c|c|}
\hline \multirow[t]{3}{*}{ Parameter } & \multicolumn{7}{|c|}{ Time-point } \\
\hline & \multicolumn{4}{|c|}{ First patient } & \multicolumn{3}{|c|}{ Second patient } \\
\hline & Baseline & $3 M$ & $6 \mathrm{M}$ & $18 \mathrm{M}$ & Baseline & $24 M$ & $48 M$ \\
\hline Cross-sections, $n$ & 12 & 19 & 24 & 20 & 11 & 13 & 13 \\
\hline Lumen area $\left[\mathrm{mm}^{2}\right]$ & $\begin{array}{c}6.55 \\
(6.21-7.15)\end{array}$ & $\begin{array}{c}5.91 \\
(5.80-6.45)\end{array}$ & $\begin{array}{c}7.03 \\
(6.12-7.40)\end{array}$ & $\begin{array}{c}7.81 \\
(6.92-8.53)\end{array}$ & $\begin{array}{c}7.45 \\
(4.65-8.75)\end{array}$ & $\begin{array}{c}4.22 \\
(3.91-4.42)\end{array}$ & $\begin{array}{c}3.81 \\
(3.51-4.12)\end{array}$ \\
\hline Min lumen diameter [mm] & $\begin{array}{c}2.62 \\
(2.51-2.65) \\
\end{array}$ & $\begin{array}{c}2.42 \\
(2.35-2.60) \\
\end{array}$ & $\begin{array}{c}2.62 \\
(2.35-2.80) \\
\end{array}$ & $\begin{array}{c}2.92 \\
(2.71-3.12) \\
\end{array}$ & $\begin{array}{c}2.81 \\
(2.25-3.05) \\
\end{array}$ & $\begin{array}{c}2.00 \\
(2.00-2.10)\end{array}$ & $\begin{array}{c}1.92 \\
(1.71-2.00) \\
\end{array}$ \\
\hline Endoluminal SA [mm²] & $\begin{array}{c}5.71 \\
(5.50-5.95) \\
\end{array}$ & $\begin{array}{c}6.21 \\
(5.91-6.72) \\
\end{array}$ & $\begin{array}{c}7.73 \\
(7.57-8.33) \\
\end{array}$ & $\begin{array}{c}8.22 \\
(7.65-9.12) \\
\end{array}$ & $\begin{array}{c}4.81 \\
(4.01-5.12) \\
\end{array}$ & $\begin{array}{c}4.82 \\
(4.51-5.23) \\
\end{array}$ & $\begin{array}{c}5.92 \\
(5.75-6.73) \\
\end{array}$ \\
\hline Out SA $\left[\mathrm{mm}^{2}\right]$ & $\begin{array}{c}7.74 \\
(7.45-7.95) \\
\end{array}$ & $\begin{array}{c}7.72 \\
(7.57-8.33) \\
\end{array}$ & $\begin{array}{c}9.31 \\
(8.26-9.81)\end{array}$ & $\begin{array}{c}10.15 \\
(9.39-11.07) \\
\end{array}$ & $\begin{array}{c}6.33 \\
(5.43-6.79) \\
\end{array}$ & $\begin{array}{c}5.92 \\
(5.7-6.7) \\
\end{array}$ & $\begin{array}{c}6.97 \\
(6.82-7.27) \\
\end{array}$ \\
\hline Eccentricity index & $\begin{array}{c}0.19 \\
(0.14-0.24) \\
\end{array}$ & $\begin{array}{c}0.19 \\
(0.16-0.22) \\
\end{array}$ & $\begin{array}{c}0.215 \\
(0.16-0.27) \\
\end{array}$ & $\begin{array}{c}0.13 \\
(0.11-0.16) \\
\end{array}$ & $\begin{array}{c}0.14 \\
(0.13-0.17) \\
\end{array}$ & $\begin{array}{c}0.19 \\
(0.15-0.22) \\
\end{array}$ & $\begin{array}{c}0.21 \\
(0.20-0.23) \\
\end{array}$ \\
\hline $\mathrm{EI}>0.3, n(\%)$ & $0 \%$ & $0 \%$ & $4(17)$ & $0 \%$ & $0 \%$ & $0 \%$ & $0 \%$ \\
\hline Scaffold struts, $n$ & 110 & 171 & 199 & 164 & 90 & 113 & 54 \\
\hline Covered struts, $n(\%)$ & - & $158(92)$ & $187(94)$ & $144(89)$ & & $101(89)$ & $54(100)$ \\
\hline Malapposed struts, $n(\%)$ & $6(5)$ & $0(0)$ & $0(0)$ & $0(0)$ & $0(0)$ & $0(0)$ & $0(0)$ \\
\hline $\mathrm{NIH}[\mu \mathrm{m}]$ & & $\begin{array}{c}700 \\
(460-1040)\end{array}$ & $\begin{array}{c}725 \\
(542-1007)\end{array}$ & $\begin{array}{c}793 \\
(683-1006)\end{array}$ & & $\begin{array}{c}952 \\
(672-1032)\end{array}$ & $\begin{array}{c}772 \\
(690-920)\end{array}$ \\
\hline Neointimal area $\left[\mathrm{mm}^{2}\right]$ & - & $\begin{array}{c}0.22 \\
(0-0.61) \\
\end{array}$ & $\begin{array}{c}0.62 \\
(0.15-0.81)\end{array}$ & $\begin{array}{c}0.71 \\
(0.51-1.05)\end{array}$ & & $\begin{array}{c}0.61 \\
(0.52-0.72)\end{array}$ & $\begin{array}{c}1.72 \\
(1.51-1.72) \\
\end{array}$ \\
\hline \multirow[t]{2}{*}{ Parameter } & & \multicolumn{6}{|c|}{$P$-values } \\
\hline & & $\begin{array}{c}\text { Baseline vs. } \\
3 \mathrm{M}\end{array}$ & $3 \mathrm{M}$ vs. $6 \mathrm{M}$ & $6 \mathrm{M}$ vs. $18 \mathrm{M}$ & & $\begin{array}{c}\text { Baseline vs. } \\
24 \mathrm{M}\end{array}$ & $\begin{array}{c}24 M \text { vs. } \\
48 M\end{array}$ \\
\hline Lumen area & & 0.041 & 0.028 & 0.007 & & 0.041 & 0.071 \\
\hline Min lumen diameter & & 0.039 & 0.257 & 0.003 & & 0.039 & 0.011 \\
\hline Endoluminal SA & & 0.003 & 0.002 & 0.005 & & 0.484 & $<0.001$ \\
\hline Out SA & & 0.498 & 0.002 & 0.004 & & 0.950 & $<0.001$ \\
\hline Eccentricity index & & 0.625 & 0.254 & $<0.001$ & & 0.062 & 0.128 \\
\hline Covered struts & & - & 0.548 & 0.039 & & - & $<0.001$ \\
\hline Malapposed struts & & 0.03 & - & - & & - & - \\
\hline $\mathrm{NIH}$ & & - & 0.455 & 0.516 & & - & 0.472 \\
\hline Neointimal area & & - & 0.058 & 0.611 & & - & $<0.001$ \\
\hline
\end{tabular}

\section{8-month follow-up after BVS implantation in SVG}

There were 26 OCT cross-sections analyzed at baseline and 17 OCT cross-sections analyzed at 48-month follow-up for both BVS. Out of 202 scaffold struts, there were only 67 (33\%) black boxes visible at 48-month follow-up. The MLA (mm², 7.45 (4.65-8.75) vs. 4 (3.51-3.01), $p<0.001)$ and MLD (2.81 (2.25-3.05) vs. 1.91 (1.81-2.21), $p<0.001)$ were smaller at 48-month follow-up as compared to baseline. The endoluminal SA (7.3 (4.85-7.9) vs. $5.5(5.2-5.7) p=0.464)$ and out SA (9.35 (6.37-10.25) vs. $7.16(6.86-7.83), p=0.691)$ decreased at 48 -month follow-up. HD-IVUS was not able to visualize struts at 48-month follow-up and presented MLA $=3.4 \mathrm{~mm}^{2}, \mathrm{MLD}=$ $2 \mathrm{~mm}, \mathrm{~PB}=44 \%$ and TPA $=2.7 \mathrm{~mm}^{2}$ and TPV $=33.7 \mathrm{~m}^{2}$ for the first patient, and $M L A=4.6 \mathrm{~mm}^{2}, M L D=2.3 \mathrm{~mm}, \mathrm{~PB}=$ $62 \%$ with TPA $=6.2 \mathrm{~mm}^{2}$ and TPV $=68.7 \mathrm{~mm}^{3}$ for the second patient. HD-IVUS also presented the echogenic rim of neointima remaining after the BVS implantation (Figure 3).
48 months after BVS implantation in SVG vs. native coronary artery

There were 41 OCT cross-sections and 268 struts analyzed in native coronary arteries and 17 cross-section and 67 struts analyzed in SVG. There were no differences in MLA (4.8 (3.6-8.9) vs. 4.0 (3.5-5), $p=0.228)$, endoluminal SA (6.15 (5.1-11.1) vs. $5.5(5.2-5.7), p=0.1048)$ and out SA (7.72 (6.61-13.38) vs. 7.16 (6.87-7.83), $p=0.3664)$ between native and SVG scaffolds. However, there was a difference in NIH thickness (1.27 (0.953$1.696)$ vs. 0.757 (0.633-0.848), $p<0.001$ ) between a native coronary artery and BVS scaffolds at 4 years follow-up.

\section{Discussion}

It is the first description of BVS healing by serial OCT imaging at long-term follow-up. The main finding of the study was as follows: 1) BVS healing in vein grafts was a dynamic process with the reduction of lumen area during 

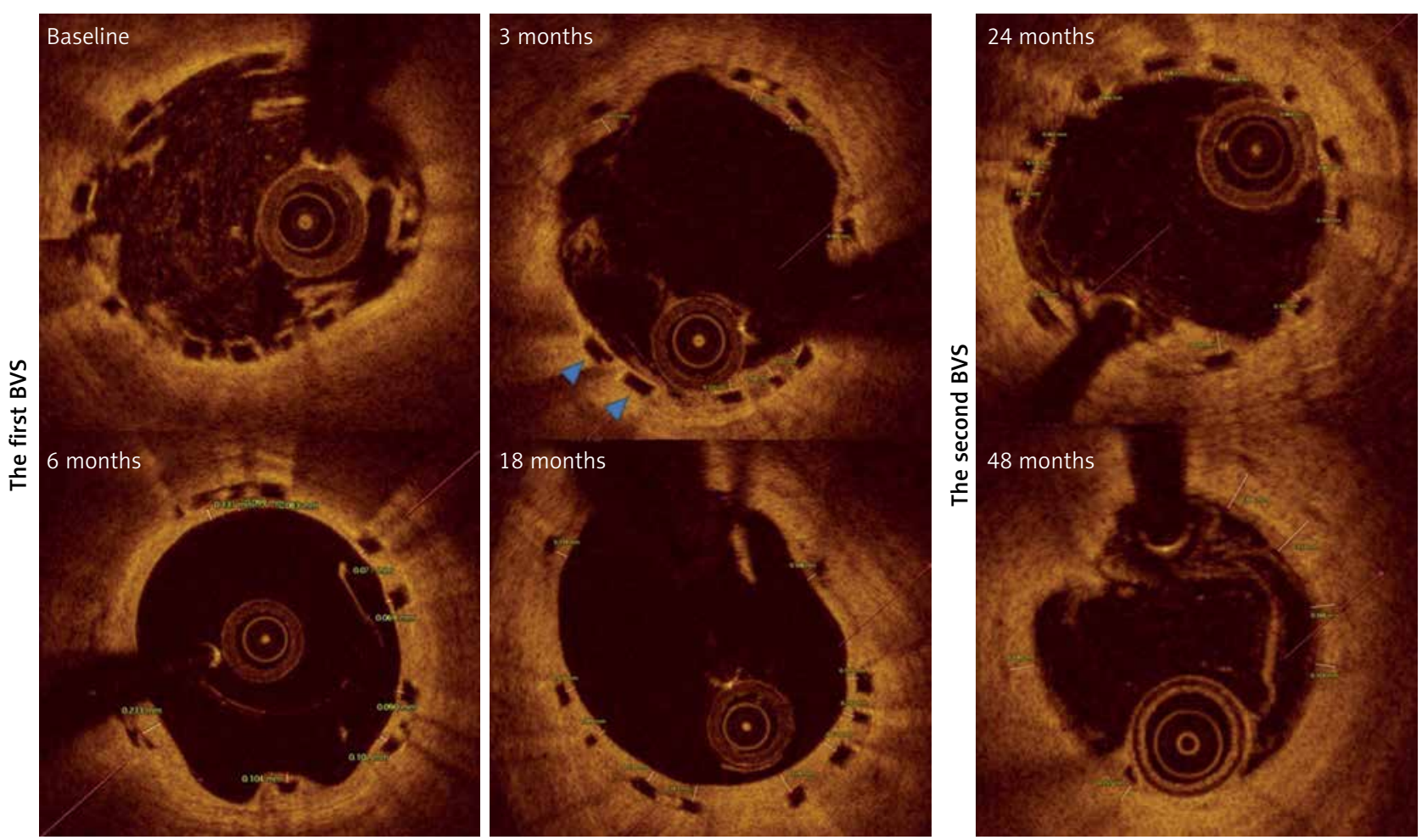

Figure 2. Representative serial OCT images of ABSORB implanted in vein graft. The figure presents OCT images of two bioresorbable vascular scaffolds (ABSORB) implanted in vein grafts at baseline, 3-, 6-, 18-, 24- and 40-month follow-up. The figure presents the measurements of neointimal thickness for every scaffolds strut.

The two blue triangles present uncovered struts of ABSORB at 3-month follow-up

the first 6 months, subsequent lumen growing up to 18 months and final lumen reduction observed at 24- and 48-month follow-up. The observed lumen remodeling was not accompanied by increasing neointimal hyperplasia. 2) OCT imaging presented $33 \%$ of remaining scaffold black boxes, and HD-IVUS imaging revealed a significant plaque burden and neointimal rim at the site of BVS implantation at 48-month follow-up. 3) The vessel remodeling that occurred after BVS implantation was similar in vein grafts and native coronary arteries at 48-month follow-up. 4) The scaffold coverage was not complete in vein grafts until the $48^{\text {th }}$ month after implantation.

The previous data from native coronary arteries indicated that neointimal hyperplasia was observed during the first 24 months after the BVS implantation. It was observed in stable coronary patients as well as in those with ACS. For both stable CAD and acute coronary patients, the fast NIH was observed in the first year after implantation, and then it slowed down. The neointima was $\sim 600 \mu \mathrm{m}$ thick at 12 months after BVS implantation in stable CAD patients [17], and $\sim 300 \mu \mathrm{m}$ or $\sim 430 \mu \mathrm{m}$ in STEMI patients at 12- and 24-month follow-up respectively [18]. The observed BVS healing in the vein graft showed that the thickness of neointima $(\sim 600 \mu \mathrm{m})$ at 24-month follow-up was similar to that observed in BVS implanted in patients with stable CAD at 24-month follow-up and was twice as thick as in patients with STEMI
$[17,18]$. There was also no significant increase in $\mathrm{NIH}$ after 3 months of BVS implantation in the vein graft, suggesting its faster healing.

In our study, we observed a nearly complete scaffold coverage at 3-month follow-up, which is in line with previous reports [13]. Long-term observation showed a stable thickness of BVS coverage in the vein graft, but full scaffold coverage was observed only at 48-month follow-up. It is in contrast with data obtained from BVS implanted in native coronary arteries [19]. Almost complete ( 99\%) coverage was found after BVS implantation in stable CAD and STEMI patients at 12-month follow-up [17, 18].

Interestingly, the vein graft lumen presented dynamic remodeling after BVS implantation, which is not in line with previous reports. The BVS lumen area remained stable after 12 months in both patients with stable CAD and ACS $[18,20]$. Previous studies also showed constant remodeling of the vessel eccentricity in the first 24 months after BVS implantation in SCAD [10, 21]. However, a higher percentage of eccentric lesions was observed after the index procedure, within a time the vessel concentricity increased and remained stable after 2 years. Our study showed that BVS characterized stable scaffold concentricity up to 48 months after the implantation. It may be explained by the fact that vein graft lesions are less calcified and thus an appropriate scaffold shape was much more easily achieved as com- 

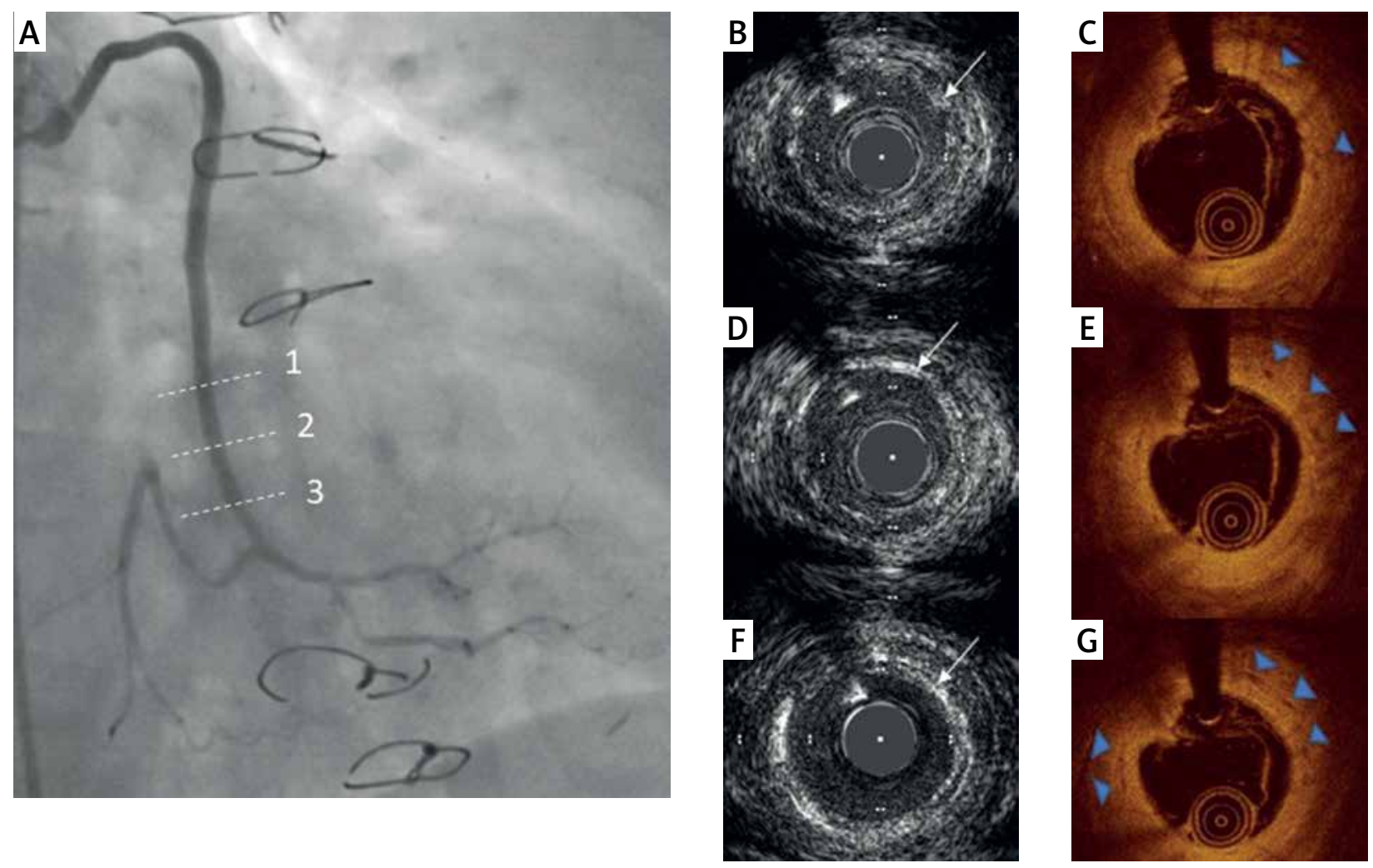

Figure 3. Representative angiography, OCT and HD-IVUS imaging of ABSORB implanted in the vein graft at 48-month follow-up. A - The coronary angiography presents the vein graft 48 months after ABSORB implantation. The dashed lines indicate $(1,2,3)$ the position of HD-IVUS (B, D, F) and OCT cross-section images (C, E, $\mathbf{G )}$. The white arrows indicate the echogenic rim of the remaining neointima (B, D, F) and blue triangles indicate black boxes remaining (C, E, G) after ABSORB implantation

pared to native coronary arteries [22, 23]. Additionally, the stable BVS shape may explain the lack of malapposition during the follow-up, which in line with the animal model observations [24], but in contrast to human studies. BVS malapposition was observed even up to 36 months after the implantation [20]. Interestingly, HD-IVUS presented an echogenic rim at 48 months after implantation. Since the OCT images did not present calcifications, the rim represents the acoustic tissue properties at the site of BVS implantation. Further studies are warranted to determine what is left in the vessel wall after BVS absorption.

This is the first report presenting the 48-month results of BVS implantation in vein grafts in comparison to native coronary arteries. It showed that NIH analyzed on the remaining scaffold was higher as compared to that observed in native coronary arteries. This, together with incomplete scaffold strut coverage, suggests that the BVS is less favorable to vessel healing in vein grafts. Greater $\mathrm{NIH}$ may be promoted by the lower shear stress in the SVG, as compared to native coronary arteries [25]. Furthermore, IVUS data revealed hypoechogenic lesions at the site of BVS implantation at 48-month follow-up, but their burden did not differ from those observes 3 years af- ter BVS implantation in native coronary arteries [20]. The previous report documented progression of calcification at the segment of previous BVS implantation [26].

\section{Study limitations}

The study enrolled a small number of patients, which is the main limitation. The serial intravascular imaging assessment was performed only in 2 patients, which makes it hard to draw any general conclusion from these observations. Unfortunately, it was impossible to enroll more patients because the distribution of ABSORB was stopped during the study period. The results come merely from the cross-sectional analysis. There was no propensity matching between patients with BVS implanted in vein grafts and native coronary arteries, which could also bias the comparison of vessel healing between these two clinical scenarios.

\section{Conclusions}

The serial intravascular imaging of BVS implanted in the SVG presented dynamic lumen remodeling but with stable scaffold concentric shape. The neointimal hyperplasia was not excessive, but the scaffold coverage was not complete even 24 months after the implantation. 
HD-IVUS presented a remaining plaque at the site of BVS implantation at 48-month follow-up.

\section{Acknowledgments}

The study was sponsored by a Research Grant of the Association for Cardiovascular Interventions, Polish Cardiac Society, in cooperation with Abbott Laboratories Poland Sp. z 0.o. (Warsaw, Poland).

\section{Conflict of interest}

The authors declare no conflict of interest.

\section{References}

1. Ormiston JA, Serruys PW, Regar E, et al. A bioabsorbable everolimus-eluting coronary stent system for patients with single de-novo coronary artery lesions (ABSORB): a prospective open-label trial. Lancet 2008; 371: 899-907.

2. Onuma Y, Serruys PW, Ormiston JA, et al. Three-year results of clinical follow-up after a bioresorbable everolimus-eluting scaffold in patients with de novo coronary artery disease: the ABSORB trial. Eurolntervention 2010; 6: 447-53.

3. Naganuma T, Kawamoto $H$, Panoulas VF, et al. Mid-term clinical outcomes of ABSORB bioresorbable vascular scaffold versus everolimus-eluting stent for coronary bifurcation lesions. Int J Cardiol 2017; 246: 26-31.

4. Gheorghe L, Millan X, Jimenez-Kockar M, et al. Bioresorbable Vascular Scaffolds in coronary chronic total occlusions. Clinical, vasomotor and optical coherence tomography findings at 3-year follow-up (ABSORB-CTO study). Eurolntervention 2019; 15: 99 107.

5. Roleder T, Wanha W, Smolka G, et al. Bioresorbable vascular scaffolds in saphenous vein grafts (data from OCTOPUS registry). Postep Kardiol Inter 2015; 11: 323-6.

6. Onuma Y, Grundeken MJ, Nakatani S, et al. Serial 5-year evaluation of side branches jailed by bioresorbable vascular scaffolds using 3-dimensional optical coherence tomography: insights from the ABSORB Cohort B Trial (A Clinical Evaluation of the Bioabsorbable Everolimus Eluting Coronary Stent System in the Treatment of Patients With De Novo Native Coronary Artery Lesions). Circ Cardiovasc Interv 2017; pii: e004393. doi: 10.1161/ CIRCINTERVENTIONS.116.004393.

7. Costa JR Jr, Abizaid A, Whitbourn R, et al. Three-year clinical outcomes of patients treated with everolimus-eluting bioresorbable vascular scaffolds: final results of the ABSORB EXTEND trial. Catheter Cardiovasc Interv 2019; 93: E1-7.

8. Patel A, Nazif T, Stone GW, et al. Intraluminal bioresorbable vascular scaffold dismantling with aneurysm formation leading to very late thrombosis. Catheter Cardiovasc Interv 2017; 89: 876-9.

9. Neumann FJ, Sousa-Uva M, Ahlsson A, et al. 2018 ESC/EACTS Guidelines on myocardial revascularization. Eur Heart J 2019; 40: 87-165.

10. Suwannasom P, Sotomi Y, Asano T, et al. Change in lumen eccentricity and asymmetry after treatment with Absorb bioresorbable vascular scaffolds in the ABSORB cohort B trial: a five-year serial optical coherence tomography imaging study. Eurolntervention 2017; 12: e2244-52.

11. Ong PJ, Jafary FH, Ho HH. "First-in-man" use of bioresorbable vascular scaffold in saphenous vein graft. Eurolntervention 2013; 9: 165.
12. Roleder T, Ochala A, Smolka G, et al. Implantation of a bioabsorbable vascular scaffold into a coronary vein graft: a twoweek angiography follow-up. Kardiol Pol 2014; 72: 281.

13. Roleder T, Parma Z, Smolka G, et al. Optical coherence tomography imaging of everolimus-eluting bioresorbable vascular scaffold implanted into coronary vein graft at 3-month follow-up. Eur Heart J 2014; 35: 2207.

14. Picard F, Marquis-Gravel G, Avram R, et al. Everolimus-eluting bioresorbable vascular scaffold implantation to treat saphenous vein graft disease, single-center initial experience. J Interv Cardiol 2017; 30: 433-9.

15. Gutierrez-Chico JL, Gijsen F, Regar E, et al. Differences in neointimal thickness between the adluminal and the abluminal sides of malapposed and side-branch struts in a polylactide bioresorbable scaffold: evidence in vivo about the abluminal healing process. JACC Cardiovasc Interv 2012; 5: 428-35.

16. Gomez-Lara J, Radu M, Brugaletta S, et al. Serial analysis of the malapposed and uncovered struts of the new generation of everolimus-eluting bioresorbable scaffold with optical coherence tomography. JACC Cardiovasc Interv 2011; 4: 992-1001.

17. Ormiston JA, Serruys PW, Onuma Y, et al. First serial assessment at 6 months and 2 years of the second generation of absorb everolimus-eluting bioresorbable vascular scaffold: a multi-imaging modality study. Circ Cardiovasc Interv 2012; 5: 620-32.

18. Kochman J, Koltowski L, Tomaniak M, et al. First serial optical coherence tomography assessment at baseline, 12 and 24 months in STEMI patients treated with the second-generation Absorb bioresorbable vascular scaffold. Eurolntervention 2018; 13: e2201-9.

19. Liang M, Tan HC, Low AF. Three-year follow-up optical coherence tomography of under-expanded drug-eluting stent in-stent restenosis treated with ABSORB bioresorbable vascular scaffold following ultra-high pressure pre-dilatation. J Cardiol Cases 2018; 17: 4-8.

20. Serruys PW, Onuma Y, Garcia-Garcia HM, et al. Dynamics of vessel wall changes following the implantation of the absorb everolimus-eluting bioresorbable vascular scaffold: a multi-imaging modality study at $6,12,24$ and 36 months. Eurolntervention 2014; 9: 1271-84.

21. Zhang YJ, lqbal J, Nakatani S, et al. Scaffold and edge vascular response following implantation of everolimus-eluting bioresorbable vascular scaffold: a 3-year serial optical coherence tomography study. JACC Cardiovasc Interv 2014; 7: 1361-9.

22. Roleder T, Pociask E, Wanha W, et al. Optical Coherence Tomography of De Novo Lesions and In-Stent Restenosis in Coronary Saphenous Vein Grafts (OCTOPUS Study). Circ J 2016; 80: 1804-11.

23. Kubiak GM, Pociask E, Wanha W, et al. Saphenous graft atherosclerosis as assessed by optical coherence tomography data for stenotic and non-stenotic lesions from the OCTOPUS registry. Adv Interv Cardiol 2018; 14: 157-66.

24. Strandberg E, Zeltinger J, Schulz DG, et al. Late positive remodeling and late lumen gain contribute to vascular restoration by a non-drug eluting bioresorbable scaffold: a four-year intravascular ultrasound study in normal porcine coronary arteries. Circ Cardiovasc Interv 2012; 5: 39-46.

25. Morinaga K, Okadome K, Kuroki $M$, et al. Effect of wall shear stress on intimal thickening of arterially transplanted autogenous veins in dogs. J Vasc Surg 1985; 2: 430-3.

26. Zeng $Y$, Tateishi $H$, Suwannasom P, et al. Progression of calcification after implantation of a fully bioresorbable scaffold: a serial and combined IVUS-OCT follow-up of 5years. Int J Cardiol 2016; 209: 176-8. 